\title{
Article \\ Differential Expression of Amanitin Biosynthetic Genes and Novel Cyclic Peptides in Amanita molliuscula
}

\author{
Yunjiao Lüli ${ }^{1,2,3}$, Shengwen Zhou ${ }^{1,2,4} \oplus$, Xuan Li ${ }^{5}$, Zuohong Chen ${ }^{6} \oplus$, Zhuliang Yang ${ }^{1,2}$ and Hong Luo ${ }^{1,2, *}$ \\ 1 Yunnan Key Laboratory for Fungal Diversity and Green Development, Kunming Institute of Botany, \\ Chinese Academy of Sciences, Kunming 650201, China; lvliyunjiao@mail.kib.ac.cn (Y.L.); \\ zhoushengwen@mail.kib.ac.cn (S.Z.); fungi@mail.kib.ac.cn (Z.Y.) \\ 2 CAS Key Laboratory for Plant Diversity and Biogeography of East Asia, Kunming Institute of Botany, \\ Chinese Academy of Sciences, Kunming 650201, China \\ 3 University of Chinese Academy of Sciences, Beijing 100049, China \\ 4 School of Life Sciences, Yunnan University, Kunming 650091, China \\ 5 Department of Environmental Science and Engineering, Kunming University of Science and Technology, \\ Kunming 650091, China; x.li@hotmail.com \\ 6 College of Life Science, Hunan Normal University, Changsha 410081, China; chenzuohong@263.net \\ * Correspondence: luohong@mail.kib.ac.cn
}

check for updates

Citation: Lüli, Y.; Zhou, S.; Li, X.;

Chen, Z.; Yang, Z.; Luo, H.

Differential Expression of Amanitin Biosynthetic Genes and Novel Cyclic Peptides in Amanita molliuscula. J.

Fungi 2021, 7, 384. https://

doi.org/10.3390/jof7050384

Academic Editor: Willem Melchers

Received: 28 April 2021

Accepted: 12 May 2021

Published: 14 May 2021

Publisher's Note: MDPI stays neutral with regard to jurisdictional claims in published maps and institutional affiliations.

Copyright: (C) 2021 by the authors Licensee MDPI, Basel, Switzerland. This article is an open access article distributed under the terms and conditions of the Creative Commons Attribution (CC BY) license (https:// creativecommons.org/licenses/by/ $4.0 /)$.

\begin{abstract}
Amanita molliuscula is a basal species of lethal Amanita and intrigues the field because it does not produce discernable $\alpha$-amanitin when inspected by High Performance Liquid Chromatography (HPLC), which sets it apart from all known amanitin-producing (lethal) Amanita species. In order to study the underlining genetic basis of the phenotype, we sequenced this species through PacBio and Illumina RNA-Seq platforms. In total, 17 genes of the "MSDIN" family (named after the first five amino acid residues of the precursor peptides) were found in the genome and 11 of them were expressed at the transcription level. The expression pattern was not even but in a differential fashion: two of the MSDINs were highly expressed (FPKM value $>100$ ), while the majority were expressed at low levels (FPKM value $<1$ ). Prolyl oligopeptidease B (POPB) is the key enzyme in the amanitin biosynthetic pathway, and high expression of this enzyme was also discovered (FPKM value $>100$ ). The two MSDINs with highest transcription further translated into two novel cyclic peptides, the structure of which is distinctive from all known cyclic peptides. The result illustrates the correlation between the expression and the final peptide products. In contrast to previous HPLC result, the genome of $A$. molliuscula harbors $\alpha$-amanitin genes (three copies), but the product was in trace amount indicated by MS. Overall, transcription of MSDINs encoding major toxins ( $\alpha$-amanitin, $\beta$-amanitin, phallacidin and phalloidin) were low, showing that these toxins were not actively synthesized at the stage. Collectively, our results indicate that the amanitin biosynthetic pathway is highly active at the mature fruiting body stage in A. molliuscula, and due to the differential expression of MSDIN genes, the pathway produces only a few cyclic peptides at the time.
\end{abstract}

Keywords: poisonous mushroom; genome; transcriptome; MSDIN family; MS

\section{Introduction}

The lethal doses of amanitins, members of the amatoxin group of bicyclic octapeptides, are extremely low, and a mature fruiting body of an amanitin-producing mushroom can cause death of an adult human being [1]. According to statistics from the China Center for Disease Control and Prevention (China CDC) from 2010 to 2020, there were 8007 poisoning incidents caused by poisonous mushrooms in China with 733 deaths [2-4]. Among them, the amanitin-containing mushrooms caused the majority (68.0-90.9\%) of those deaths. Amanita species mainly include two types of cyclic peptides: amatoxins and phallotoxins $[1,5]$. Amatoxins are highly effective inhibitors of RNA polymerase II in eukaryotes, while phallotoxins irreversibly bind to F-actin filaments in the cytoskeleton, interrupting 
the dynamic process of polymerization and depolymerization [6,7]. Despite the toxicity, amanitin-antibody conjugate has been considered as a potential cancer treatment $[8,9]$. The biosynthesis of amatoxins is mainly completed by two important groups of genes: those in the "MSDIN" family, which encode the precursors of the cyclic peptides; and prolyl oligopeptidase $\mathrm{B}(P O P B)$, which specifically recognizes the proproteins, and cleaves and macrocyclizes them into unmodified cyclic peptides [10-12].

Amatoxins, phallotoxins and other related cyclic peptides are distributed in several genera of different families in the order Agaricales, i.e., Amanita, Lepiota and Galerina. The distribution of amanitin biosynthetic genes in the three genera is a result of horizontal gene transfer $[13,14]$. In Amanita, there are several shared major toxins, i.e., $\alpha$-amanitin, $\beta$-amanitin, phalloidin and phallacidin [1,5], while Galerina and Lepiota have primarily $\alpha$-amanitin (with small amounts of $\beta$-amanitin in a few cases) $[14,15]$. Amanita is probably the last genus to obtain the ability for the toxin production, but clearly it has advanced the capability by producing diversified cyclic peptides [13].

Lethal Amanita species are restricted to sect. Phalloideae, and the basal most species do not contain the toxins [16]. Basal amanitin-producing species are therefore valuable for insights into the origin and evolution of the pathway in the genus. Amanita molliuscula is just such a species, and several labs have confirmed that its toxin-phenotype is unique as HPLC analysis does not show discernable $\alpha$-amanitin production (personal communications). Because $\alpha$-amanitin is present in all other known amanitin-producing mushrooms in Agaricales [4,5], this species would serve as a great model for studying the genetic basis underlining the phenotype. Although genomes of Amanita species are becoming more available, expression studies of the amanitin biosynthetic genes are still limited to yes/no level. The first report on the amanitin biosynthetic pathway showed that $A M A 1$, an $\alpha$ amanitin-encoding MSDIN, and PHA1, a phallacidin-encoding MSDIN, are transcribed in mature carpophores [12]. Later, 11 MSDINs were shown to be transcribed in A. exitialis, and in total 4 cyclic peptides were found [17]. In A. bisporigera and A. phalloides, half of the unknown MSDIN genes were shown to be transcribed [18]. Our recent report showed over $80 \%$ of MSDINs were transcribed in A. subjunquillea [19]. The reports so far have indicated that not every MSDIN is expressed, so MSDINs are likely not coregulated. Further, it is unknown to what extent the expression level correlates with final cyclic peptide product abundance. Detailed data on the expression of MSDIN and other amanitin biosynthetic genes is still lacking.

In this study, A. molliuscula was sequenced via PacBio and Illumina RNA-Seq platforms. The MSDIN and POPB genes were analyzed at both genomic and transcriptomic levels. In addition, cyclic peptide products were analyzed through our genome-guided approach [19], and correlation between expression level and final cyclic peptide products was carefully assessed.

\section{Materials and Methods}

\subsection{Sample}

The mushroom fruiting body used in this study was A. molliuscula Qing Cai, Zhu L. Yang \& Yang-Yang Cui, a rare species found in China. This particular specimen was collected in Changbai mountains, Jilin Province, Northeast China. The fresh specimen (designated A. molliuscula Jilin-China) was identified by Zhu L. Yang. The Latin molliusculus refers to the somewhat soft volval limb of the species composed of abundant inflated cells [20]. The type specimen was deposited in the Herbarium of Cryptogams, Kunming Institute of Botany [20], Chinese Academy of Sciences (type, HKAS 77324). The fruiting body was wrapped in aluminum foil on site, immediately put on dry ice, and subsequently stored in liquid nitrogen before use.

\subsection{Phylogenetic Tree Construction}

To confirm the phylogenetic position of A. molliuscula among lethal amanitas, a phylogenetic tree was constructed using ITS (internal transcribed spacer) of 12 species from 
Europe, North America and Asia. These species are A. bisporigera, A. phalloides, A. virosa, A. molliuscula, A. pallidorosea, A. subpallidorosea, A. rimosa, A. subjunquillea, A. fuliginea, A. exitialis, $A$. franzii and $A$. zangii. Two of the species, $A$. franzii and $A$. zangii, are nontoxigenic and were used as outgroups. Internal transcribed spacer sequences were obtained from NCBI website (https:/ / www.ncbi.nlm.nih.gov/, accessed on 12 December 2020), and from the sequenced genome in this study. The gene accession numbers and sequence information are listed in supplementary file S1. Sequences were aligned by MAFFT v7.304b [21] with default settings, and then manually adjusted with BioEdit [22]. Maximum Likelihood analyses and bootstrapping (1000 replicates) were performed using RAxML v7 [23]. For Bayesian inference analyses, MrBayes v3.2.6 [24] was used under the optimal substitution model obtained from MrModeltest [25].

\subsection{Genome Sequencing and Assembly}

The genome of $A$. molliuscula was sequenced and assembled by NextOmics Biosciences, Wuhan, China. The specific process was as follows. Genomic DNA was extracted by Genomic DNA extraction kit (QIAGEN, Germantown, MD, USA) according to the standard operating procedure provided by the manufacturer. The genomic DNA was then sheared by g-TUBEs (Covaris, Woburn, MA, USA) according to the expected size $(20 \mathrm{~kb})$ of the fragments for the library. The fragmented DNA of target size was enriched and purified by MegBeads (GenScript, Piscataway, NJ, USA). Next, the fragmented DNA was repaired for the damage and then end-repaired. A 20-kb library was then constructed using a PacBio template prep kit and analyzed with Agilent 2100 Bioanalyzer for quality control. After completion of the library, DNA-enzyme mixture was transferred to PacBio Sequel platform for real-time molecular sequencing. Illumina HiSeq X10 platform was used for error correction. The reads were assembled by Falcon (https:/ / github.com/PacificBiosciences / FALCON-integrate, accessed on 25 November 2018), and the completeness of the gene repertoires was assessed by Benchmarking Universal Single-Copy Orthologs (BUSCO) [26].

\subsection{Transcriptome Sequencing and Analysis}

Amanita molliuscula is a species forming mycorrhiza with trees and has not, to date, been cultured artificially. Only one mushroom fruiting body was obtained in this study, and three RNA extractions were made from this sample. RNA concentration was measured using Qubit RNA Assay Kit (Thermo Fisher Scientific, Waltham, MA, USA) in Qubit 2.0 Flurometer (Life Technologies, Carlsbad, CA, USA). RNA integrity was assessed using RNA Nano 6000 Assay Kit (Agilent Technologies, Santa Clara, CA, USA) with the Bioanalyzer 2100 system (Agilent Technologies, Santa Clara, CA, USA). The mRNA was purified from total RNA using poly-T oligo-attached magnetic beads. First strand cDNA was synthesized using random hexamer primer and M-MuLV Reverse Transcriptase (New England BioLabs, Ipswich, MA, USA). Second strand cDNA synthesis was subsequently performed using DNA Polymerase I (New England BioLabs, Ipswich, MA, USA) and RNase H (New England BioLabs, Ipswich, MA, USA). Library quality was assessed on the Agilent Bioanalyzer 2100 system, and transcriptome sequencing performed on Illumina RNA-Seq platform. The quality control of the raw data was carried out with FastP software under default settings [27]. Hisat2 [28] was used to align transcriptome reads and to generate Sam format file, and SAMtools [29] adopted to convert large Sam files into binary BAM format file. The Subread software was used to calculate the read counts [30], and the DESeq2 was subsequently adopted to analyze the differential gene expression of the three transcriptomes [31]. Finally, the assemblies and FPKM values (Fragments Per Kilobase of transcript per Million fragments mapped) were obtained using StringTie with default settings [32].

\subsection{Venn Diagram Construction}

In order to show orthologous gene groups in six lethal amanitas (A. molliuscula, A. bisporigera, A. phalloides, A. exitialis, A. pallidorosea and A. subjunquillea), OrthoFinder [33] 
was used with default program settings. The outputs were uploaded to JVENN (http:/ / jvenn.toulouse.inra.fr/app/example.html, accessed on 5 March 2020) for diagram construction.

\subsection{Visualization of the Genome}

Visualization software Circos [34] was chosen to map the genome and amanitin biosynthetic genes. The information tracks included location and size of each contig, GC content, gene transcription (FPKM values), distribution of amanitin biosynthetic genes, prediction of genes, transposons and synteny analysis. The GC content was calculated by our in-house scripts. The gene transcription was indicated by FPKM values, and the coordinate information of amanitin biosynthetic genes was obtained by BLAST (NCBI BLAST+ 2.6.0). Synteny was calculated by blastn module. The information was written into seven tracks and loaded into Circos for a genomic overview of $A$. molliuscula.

The synteny analysis of three species producing lethal toxins (A. molliuscula, A. pallidorosea and A. exitialis) was conducted via SyMAP (Synteny Mapping and Analysis Program) 5.0.6 [35]. All alignments were computed using the default parameters. All scaffolds or contigs for all the genomes were loaded in the program.

\subsection{LC-MS and LC-MS/MS Analyses for Novel Cyclic Peptides}

For cyclic peptide extraction, $0.05 \mathrm{~g}$ dry weight sample was ground in liquid nitrogen. Then $2 \mathrm{~mL}$ buffer was added, using methanol: water: $0.01 \mathrm{M}$ hydrochloric acid $(5: 4: 1)[36,37]$. The suspension was transferred to centrifuge tubes, and then heated in a water bath at $75{ }^{\circ} \mathrm{C}$ for $15 \mathrm{~min}$, followed by centrifugation $(12,000 \mathrm{rpm})$ for $5 \mathrm{~min}$. Finally, the supernatant was filtered with a $0.22 \mu \mathrm{m}$ polyethersulfone syringe filter (BS-PES22, Biosharp).

Liquid chromatography-mass spectrometry (LC-MS) and liquid chromatographytandem mass spectrometry (LC-MS/MS) analyses were conducted through Agilent 1290 Infinity II HPLC system with column $(4.6 \times 100 \mathrm{~mm}$ I.D., particle size $2.7 \mu \mathrm{m}$, Agilent Technologies). To detect potential cyclic peptides of A. molliuscula, the filtered supernatant was applied on Agilent 6540 UHD precision mass quadrupole time-of-flight (Q-TOF) LC/MS (Agilent Technologies, Santa Clara, CA, USA). The eluent was monitored in positive electrospray ionization (ESI) mode with the capillary voltage at $3.5 \mathrm{kV}$. The drying gas $\left(\mathrm{N}_{2}\right)$ temperature was $350{ }^{\circ} \mathrm{C}$, and the flow rate was $8 \mathrm{~L} / \mathrm{min}$. The mass scan range was $500-1700 \mathrm{~m} / \mathrm{z}$. For collision energy in the subsequent MS/MS analysis, a range of 10-70 eV was applied.

For the prediction of monoisotopic masses and molecular formula of potential novel cyclic peptides based on MSDIN sequences, the online calculation tool NCBI MIDAs (https: //www.ncbi.nlm.nih.gov/CBBresearch/Yu/midas/index.html, accessed on 12 October 2019) was adopted. Then, iminium ions, y-type fragmentation and neutral loss ions were determined based on core peptides of MSDINs using Molecular Weight Calculator v6.50 (https:/ / omics.pnl.gov/software/molecular-weight-calculator, accessed on 5 July 2019). All amino acid composition and manual MS/MS analysis for novel cyclic peptides were based on our genome-guided method [19].

\subsection{Cloning of MSDIN and POPB Genes in A. molliuscula}

Nucleotide sequences of MSDINs and $P O P B$ genes from the A. molliuscula genome were obtained by BLAST (NCBI BLAST+ 2.6.0). Query MSDIN and POPB sequences came from A. bisporigera and Galerina marginata [15,18], and the detailed search strategy can be found in our recent report [19]. The nucleotide sequences of MSDINs and POPB genes of $A$. molliuscula were aligned with those of $A$. bisporigera by MegAlign v7.1.0. Coding sequences (CDS) of MSDINs and AmPOPB ( $A m$ are the initials of the species and are applied throughout the report) were obtained by reverse transcription PCR (RT-PCR) using primers based on the genomic data. First and second strands of cDNA were obtained using the methods mentioned above. In the genome of A. molliuscula, there were three MSDINs encoding $\alpha$-amanitin. The corresponding amino acid sequences were MSDINATRLPIWGIGC- 
NPCVGDDVTTLLTRGEALC and MSDINATRLAIWGIGCNPCVGDDVTALLTRGEALC (two identical sequences), which were named AmAMA1, AmAMA2-1 and AmAMA2-2, respectively. And the gene encoding $\beta$-amanitin was named $A m A M A 3$. Two novel cyclic peptides, CylK1 (named $A m C y l K 1$ ) and CylK2 (named $A m C y l K 2$ ), were discovered in this study (see results). The primers are shown in supplementary file S2. The structures of the genes were illustrated using the coding sequences (CDS) and genomic DNA sequences on Splign website (https:/ / www.ncbi.nlm.nih.gov/sutils/splign/splign.cgi, accessed on 16 June 2020).

\section{Results}

\subsection{Phylogenetic Position of A. molliuscula}

The genus Amanita contains three major clades and 11 subclades [38], among which sect. Phalloideae possesses three subclades and one of them includes all known lethal amanitas [38,39]. In order to illustrate the phylogenetic position of $A$. molliuscula among lethal amanitas, 12 species distributed in Europe, North America and Asia were selected for reconstruction. The resultant phylogenetic tree was constructed with 33 ITS sequences, including two nontoxic outgroup species (Figure 1a). Among these species, A. molliuscula (shaded in red), including $A$. molliuscula Jilin-China used in this study (Figure 1b), was at the basal position of lethal amanitas, and the branch had robust support (ML bootstrap value $=95$, Bayesian posterior probability $=1$ ). The result is consistent with previous studies [20].
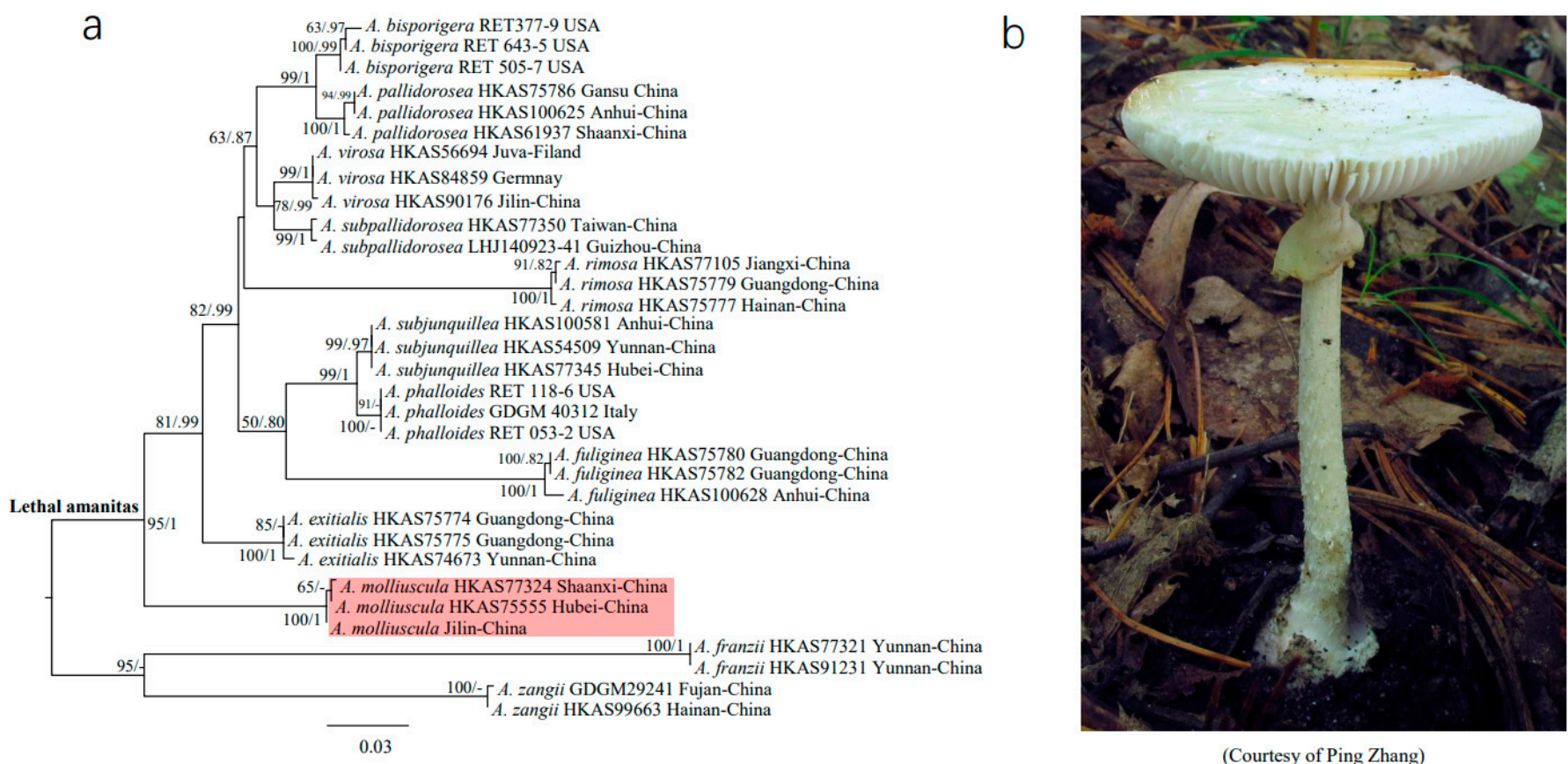

Figure 1. (a) Phylogenetic tree of lethal amanitas. (b) Amanita molliuscula in the field.

\subsection{Genome and Transcriptome of A. molliuscula}

The whole genome shotgun assembly of $A$. molliuscula has been deposited at DDBJ/ ENA/GenBank as part of the batch accession JAEBUT000000000. The assembly results are shown in Figure 2. The amount of clean data was $4.46 \mathrm{~Gb}$, the assembled genome was $71.17 \mathrm{Mbp}$ and the sequencing depth was about $60 \mathrm{x}$. BUSCO prediction with Basidiomycota settings implied that $87.3 \%$ of the core genes were found. Transposable elements (TEs) accounted for $64.78 \%$ of the genome. 


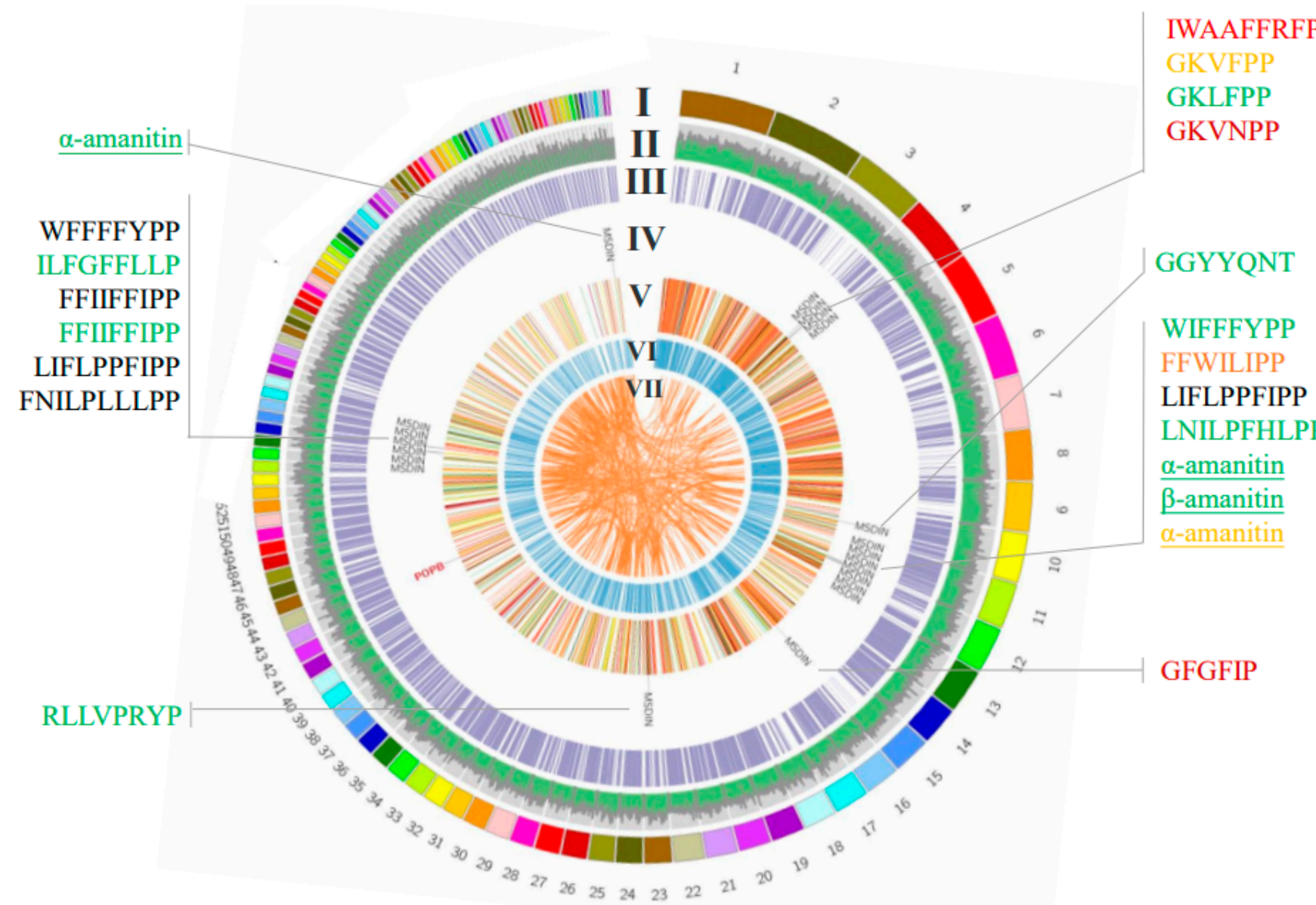

\begin{tabular}{cc}
\hline Species & Amanita molliuscula \\
\hline $\begin{array}{c}\text { Size of assembled } \\
\text { genome }\end{array}$ & $71.17 \mathrm{Mbp}$ \\
\hline Number of contigs & 155 \\
\hline N50 (bp) & 1053316 \\
N90 (bp) & 188356 \\
Maximum length & 3180309 \\
(bp) & $46.50 \%$ \\
\hline
\end{tabular}

Keys:

I Contigs

II GC content

III Transposons

IV Distribution of amanitin biosynthetic genes

V FPKM values

$$
\begin{array}{llllll}
0 & 1 & 3 & 15 & 60 & >100
\end{array}
$$

VI Genes

VII Synteny

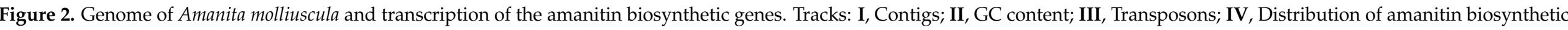

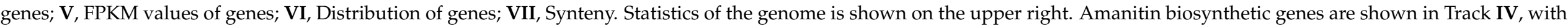
expression levels of MSDIN genes shown surrounding the genome circle (keys on the lower right). 
Because A. molliuscula is difficult to encounter in the field and cannot be cultured artificially, we used three technical replicates in the transcriptome sequencing. Differential expression analysis on the transcriptomes showed that the three replicates were highly similar, and there was no differential expression in all of the amanitin biosynthetic genes across the three replicates (Supplementary file S3). The result strongly suggested that the replicates were consistent, and one of the three transcriptomes was chosen for display in the following results.

The genome and transcriptome features were visualized as a circular diagram using Circos software (Figure 2). The tracks (from the outer ring) represented contigs, GC content, transposons, distribution of toxin biosynthetic genes, transcriptional gene expression (FPKM value), prediction of genes and synteny. In total, 17 MSDIN genes (21 sequences) were discovered with 14 being novel, and they scattered among contigs with some degree of clustering. The $A m P O P B$ gene was located on an isolated contig. Colors of track $\mathbf{V}$ represent expression levels of the predicted genes, and the same color scheme was applied to all other expression results in this report. Expression levels of amanitin biosynthetic genes ( $A m P O P B$ and MSDINs) and housekeeping genes ( $A m P O P A$ and $r b p 2$ ) were calculated, and the results shown in Table 1 and Figure 2 (color coded). The transcription of MSDIN genes varied greatly, with FPKM ranging from 0 to 357.26. The expression of most MSDIN genes was low with FPKM values below 1 (black and green). Among them, the FPKM values of four genes with core peptides of LIFLPPFIPP, FFIIFFIPP, WFFFFYP and FNILPLLLPP, were 0 . The MSDIN genes encoding major toxins were largely low. The $\alpha$-amanitin-encoding gene had three copies (AmAMA1, AmAMA2-1 and AmAMA2-2) with FPKM values of 0.24, 0.15 and 2.7, respectively. The FPKM value of the $\beta$-amanitin-encoding gene (AmAMA3) was 0.78. Two MSDIN genes ( $A m C y l K 1$ and $A m C y l K 2)$ with core peptides GFGFIP and GKVNPP were highly expressed, and the FPKM values were 357.26 and 113.45, respectively. Four MSDINs were transcribed with FPKMs between 1 and 60.

Table 1. Transcription of amanitin biosynthetic and housekeeping genes of Amanita molliuscula.

\begin{tabular}{|c|c|c|c|c|c|}
\hline & & Peptides and Proteins & & KM Values & Notes \\
\hline \multirow{22}{*}{$\begin{array}{l}\text { Amanitin } \\
\text { biosynthetic } \\
\text { genes }\end{array}$} & MSDINATRLP & IWGIGCNP & CVGDDVTTLLTRGEALC & 0.24 & $\alpha$-amanitin 3 copies \\
\hline & MSDINATRLA & IWGIGCNP & CVGDDVTALLTRGEALC & 0.15 & $\alpha$-amanitin \\
\hline & MSDINATRLA & IWGIGCNP & CVGDDVTALLTRGEALC & 2.70 & $\alpha$-amanitin \\
\hline & MSDINATRLA & IWGIGCDP & CVGDDVTALLTRGEALC & 0.78 & $\beta$-amanitin \\
\hline & MSNINALRLP & GFGFIP & YASGDVDYTLTRGESLS & 357.26 & CylK1 \\
\hline & MSDINATRFP & GKVNPP & YVGDDVDDIIIRGEKLC & 113.45 & CylK2 \\
\hline & MSNINASRLP & IWAAFFRFP & CVGDEVDGILRSGESLC & 38.94 & \\
\hline & MTDINATRLP & FFWILIPP & CVDDVDNTVHSGDNLC & 4.63 & \\
\hline & MSDINATRFP & GKVFPP & YVGDDVDDIIIRGEK & 2.07 & \\
\hline & MSNINATRFP & GKLFPP & YVGDDVDDIIIRGDKLC & 0.93 & \\
\hline & MSDINASRLP & RLLVPRYP & CIDEDAEAILRSGECL & 0.90 & \\
\hline & MTDINATRLP & ILFGFFLLP & CVDGVDNTLHSGENLC & 0.66 & \\
\hline & MSDINSIHLP & GGYYQNT & FVGDDVEGILNRGERLC & 0.61 & \\
\hline & MTDINATRLP & LNILPFHLPP & CVDDVDNTLHSGENLC & 0.29 & \\
\hline & MTDINATRLP & FFIIFFIPP & CVDDVDNTLHSGENLC & 0.25 & 2 copies \\
\hline & MTDINATRLP & FFIIFFIPP & CVDDVDNTLHSGENLC & 0.00 & \\
\hline & MTDINATRLP & WIFFFYPP & CVDDVDNTLHSGENLC & 0.09 & \\
\hline & MTDINATRLP & LIFLPPFIPP & CVDDVDNTLHSGENLC & 0.00 & 2 copies \\
\hline & MTDINATRLP & LIFLPPFIPP & CVDDVDNTLHSGENLC & 0.00 & \\
\hline & MTDINATRLP & WFFFFYPP & CVDDVDNTLHSGENLC & 0.00 & \\
\hline & MTDINATRLP & FNILPLLLPP & CVDDVDNTLHSGENLC & 0.00 & \\
\hline & & POPB & & 178.43 & \\
\hline \multirow{2}{*}{$\begin{array}{l}\text { Housekeeping } \\
\text { genes }\end{array}$} & & POPA & & 6.99 & \\
\hline & & $r b p 2$ & & 46.96 & \\
\hline
\end{tabular}

The FPKM value for $A m P O P B$, a key functional gene for toxin synthesis, was 178.43, 25 times higher than that of $A m P O P A$, a housekeeping gene also belonging to the $P O P$ 
gene family. The value was also much higher than that of the other housekeeping gene rbp2. The results showed that the cyclic peptide biosynthetic pathway was highly active in A. molliuscula.

\subsection{Orthology and Synteny Analysis of A. molliuscula}

The orthology analysis of A. molliuscula, A. bisporigera, A. phalloides, A. exitialis, A. pallidorosea and A. subjunquillea is shown in Figure 3a. In total, 10,513 orthogroups were included. There were 1860 common orthogroups among the six species. Amanita bisporigera had 2158 species-specific orthogroups, which was the largest of the six species. The least was in A. phalloides, which had 819 unique orthogroups.

a

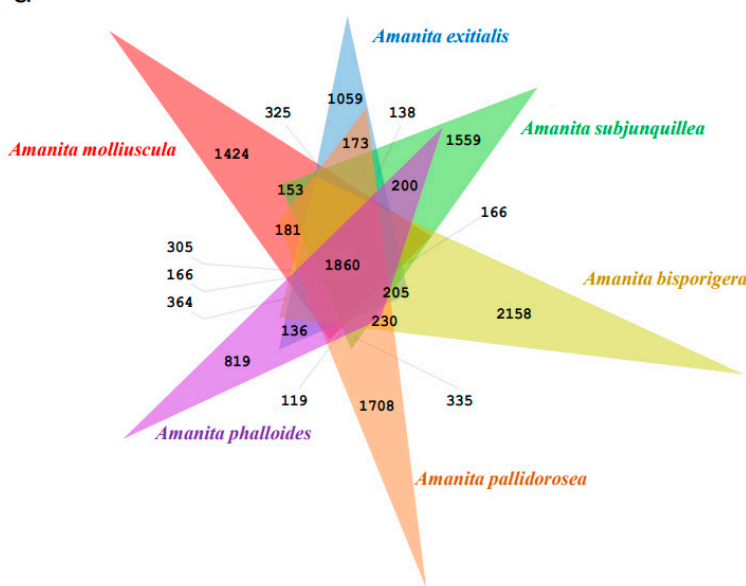

b
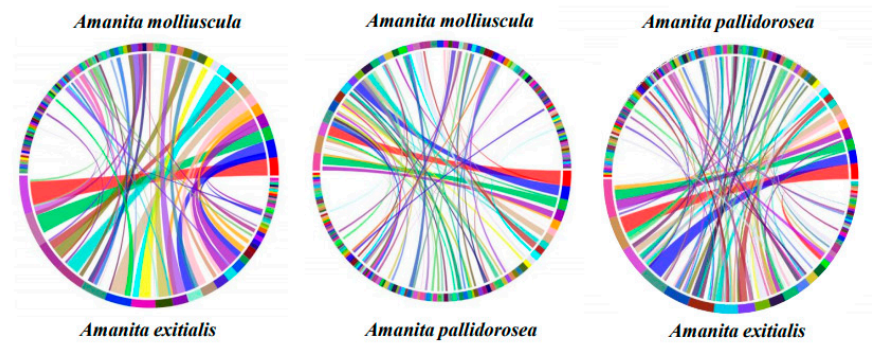

Figure 3. (a) Venn diagram of predicted orthogroups of amanitas in North America, Europe and Asia. (b) The synteny analysis of Amanita molliuscula, A. pallidorosea and A. exitialis.

In order to compare the whole genome of A. molliuscula with other lethal species, we selected A. exitialis, the closest lethal species to $A$. molliuscula, and A. pallidorosea, one of the most distant species, for synteny analysis. It was obvious that $A$. molliuscula shared more synteny with $A$. exitialis than with $A$. pallidorosea (Figure $3 b$ ), which was consistent with their phylogenetic relationships.

\subsection{Amatoxins and Novel Cyclic Peptides from A. molliuscula}

For cyclic peptide analyses, extracts of $A$. molliuscula were analyzed by HPLC, LCMS and LC-MS/MS. HPLC analysis confirmed that only $\beta$-amanitin was discernable in A. molliuscula. Following our genome-guided approach [19], we used mass spectroscopy to further investigate other potential cyclic peptides based on theoretical molecular masses of potential cyclic peptides encoded by the 17 MSDIN sequences (Table 2). $\beta$-Amanitin was readily detected, and surprisingly, a trace amount of $\alpha$-amanitin was also discovered. In addition, phallotoxin was not detected in this species.

$\alpha$-Amanitin has a formula of $\mathrm{C}_{39} \mathrm{H}_{54} \mathrm{~N}_{10} \mathrm{O}_{14} \mathrm{~S}$ and the measured mass of the $[\mathrm{M}+$ $\mathrm{H}^{+}$ion is 919.3616, with mass discrepancy of $0.22 \mathrm{ppm}$ (Figure 4a). The formula of $\beta$-amanitin is $\mathrm{C}_{39} \mathrm{H}_{53} \mathrm{~N}_{9} \mathrm{O}_{15} \mathrm{~S}$ and the measured mass of the $[\mathrm{M}+\mathrm{H}]^{+}$ion is 920.3465 , with mass discrepancy of $1.09 \mathrm{ppm}$ (Figure $4 \mathrm{~b}$ ). In addition, masses of two potential cyclic peptides were found. They match the core regions of two MSDIN sequences, i.e., MSNINALRLPGFGFIPYASGDVDYTLTRGESLS (candidate novel cyclic peptide named CylK1) and MSDINATRFPGKVNPPYVGDDVDDIIIRGEKLC (candidate novel cyclic peptide named CylK2), respectively. The core peptides were underlined. The measured molecular masses of CylK1 and CylK2 were 619.3244 and 593.3411, respectively (Figure 4c,d). Both mass discrepancies were within 1 ppm (Table 2). 
Table 2. Theoretical and measured molecular masses of cyclic peptides in Amanita molliuscula.

\begin{tabular}{|c|c|c|c|c|}
\hline Cyclic Peptides & Elemental Composition & Theoretical (m/z) & Measured $(\mathrm{m} / \mathrm{z})$ & $\delta(\mathrm{ppm})$ \\
\hline IWGIGCNP ( $\alpha$-amanitin) & $\mathrm{C}_{39} \mathrm{H}_{54} \mathrm{~N}_{10} \mathrm{O}_{14} \mathrm{~S}+\mathrm{H}^{+}$ & 919.3614 & 919.3616 & 0.2175 \\
\hline IWGIGCDP ( $\beta$-amanitin) & $\mathrm{C}_{39} \mathrm{H}_{53} \mathrm{~N}_{9} \mathrm{O}_{15} \mathrm{~S}+\mathrm{H}^{+}$ & 920.3455 & 920.3465 & 1.0865 \\
\hline GFGFIP (CylK1) & $\mathrm{C}_{33} \mathrm{H}_{42} \mathrm{~N}_{6} \mathrm{O}_{6}+\mathrm{H}^{+}$ & 619.3239 & 619.3244 & 0.8073 \\
\hline GKVNPP (CylK2) & $\mathrm{C}_{27} \mathrm{H}_{44} \mathrm{~N}_{8} \mathrm{O}_{7}+\mathrm{H}^{+}$ & 593.3406 & 593.3411 & 0.8427 \\
\hline IWAAFFRFP & $\mathrm{C}_{61} \mathrm{H}_{77} \mathrm{~N}_{13} \mathrm{O}_{9}+\mathrm{H}^{+}$ & 1136.604 & $\mathrm{~N} / \mathrm{A}$ & $\mathrm{N} / \mathrm{A}$ \\
\hline GGYYQNT & $\mathrm{C}_{35} \mathrm{H}_{45} \mathrm{~N}_{9} \mathrm{O}_{12}+\mathrm{H}^{+}$ & 784.326 & $\mathrm{~N} / \mathrm{A}$ & $\mathrm{N} / \mathrm{A}$ \\
\hline RLLVPRYP & $\mathrm{C}_{48} \mathrm{H}_{78} \mathrm{~N}_{14} \mathrm{O}_{9}+\mathrm{H}^{+}$ & 995.6149 & $\mathrm{~N} / \mathrm{A}$ & $\mathrm{N} / \mathrm{A}$ \\
\hline LNILPFHLPP & $\mathrm{C}_{58} \mathrm{H}_{87} \mathrm{~N}_{13} \mathrm{O}_{11}+\mathrm{H}^{+}$ & 1142.6721 & $\mathrm{~N} / \mathrm{A}$ & $\mathrm{N} / \mathrm{A}$ \\
\hline LIFLPPFIPP & $\mathrm{C}_{62} \mathrm{H}_{90} \mathrm{~N}_{10} \mathrm{O}_{10}+\mathrm{H}^{+}$ & 1135.6914 & $\mathrm{~N} / \mathrm{A}$ & $\mathrm{N} / \mathrm{A}$ \\
\hline FFWILIPP & $\mathrm{C}_{57} \mathrm{H}_{75} \mathrm{~N}_{9} \mathrm{O} 8+\mathrm{H}^{+}$ & 1014.5811 & $\mathrm{~N} / \mathrm{A}$ & $\mathrm{N} / \mathrm{A}$ \\
\hline FFIIFFIPP & $\mathrm{C}_{64} \mathrm{H}_{83} \mathrm{~N}_{9} \mathrm{O}_{9}+\mathrm{H}^{+}$ & 1122.6387 & $\mathrm{~N} / \mathrm{A}$ & $\mathrm{N} / \mathrm{A}$ \\
\hline WIFFFYPP & $\mathrm{C}_{63} \mathrm{H}_{71} \mathrm{~N}_{9} \mathrm{O}_{9}+\mathrm{H}^{+}$ & 1098.5448 & $\mathrm{~N} / \mathrm{A}$ & $\mathrm{N} / \mathrm{A}$ \\
\hline GKVFPP & $\mathrm{C}_{32} \mathrm{H}_{47} \mathrm{~N}_{7} \mathrm{O}_{6}+\mathrm{H}^{+}$ & 626.3661 & $\mathrm{~N} / \mathrm{A}$ & $\mathrm{N} / \mathrm{A}$ \\
\hline GKLFPP & $\mathrm{C}_{33} \mathrm{H}_{49} \mathrm{~N}_{7} \mathrm{O}_{6}+\mathrm{H}^{+}$ & 640.3817 & $\mathrm{~N} / \mathrm{A}$ & $\mathrm{N} / \mathrm{A}$ \\
\hline ILFGFFLLP & $\mathrm{C}_{58} \mathrm{H}_{81} \mathrm{~N}_{9} \mathrm{O}_{9}+\mathrm{H}^{+}$ & 1048.623 & $\mathrm{~N} / \mathrm{A}$ & $\mathrm{N} / \mathrm{A}$ \\
\hline WFFFFYPP & $\mathrm{C}_{66} \mathrm{H}_{69} \mathrm{~N}_{9} \mathrm{O}_{9}+\mathrm{H}^{+}$ & 1132.5291 & $\mathrm{~N} / \mathrm{A}$ & $\mathrm{N} / \mathrm{A}$ \\
\hline FNILPLLLPP & $\mathrm{C}_{58} \mathrm{H}_{91} \mathrm{~N}_{11} \mathrm{O}_{11}+\mathrm{H}^{+}$ & 1118.6972 & $\mathrm{~N} / \mathrm{A}$ & $\mathrm{N} / \mathrm{A}$ \\
\hline
\end{tabular}

MS/MS fragments of CylK1 and CylK2 underwent further manual analyses. For CylK1, iminium ions for Ile and Phe were found, and the measured daughter ions were 86.0967 and 120.0808, respectively (Figure 4e). Then, 7 y-type ions were confirmed according to the core peptide sequence, i.e., GP, GF, GGI, GFP, GFPIG, GFPIF and GFPFG. Based on the result, CylK1 was determined to be a novel cyclic peptide.

Similar procedures were applied to CylK2 (Figure 4f). Eleven fragments were matched with predicted ions based on the core peptide sequence. First, Pro was found by iminium ions, with the daughter ion mass at 70.0654. Then, the y-type ions, GP, GK, GKP, KPP, GPPN, GKPP and GKPPN, were matched with fragmentation ions. In addition, loss of neutral ion $\left(\mathrm{NH}_{3}\right)$ was detected on three fragments in MS/MS, and the following analyses showed that it was due to the loss of $\mathrm{NH}_{3}$ on Lys. Collectively, the results strongly suggested CylK2 to be a novel cyclic peptide.

\subsection{Structures of AmPOPB, AmAMA1, AmAMA2, AmAMA3, AmCylK1 and AmCylK2}

The MSDIN genes of $A$. molliuscula encode no phallotoxins (consistent with the MS result) but two known amatoxins, i.e., $\alpha$-amanitin and $\beta$-amanitin. There were three sequences encoding $\alpha$-amanitin (AmAMA1, AmAMA2-1 and AmAMA2-2). AmAMA1 and $A m A M A 2$ differed in the leader peptide region (MSDINATRLP vs. MSDINATRLA) and in recognition sequences (CVGDDVTTLLTRGEALC vs. CVGDDVTALLTRGEALC). The last amino acid of $A m A M A 2$ in the leader peptide region was Ala residue. There was only one sequence encoding $\beta$-amanitin, and the last amino acid in the leader peptide region of this sequence was also Ala residue. In contrast, this particular site in all other MSDIN sequences is Pro residue [12-15,17,40,41]. Both AmCylK1 and AmCylK2 coded for 6-aa peptides.

The gene structure of the above five MSDIN genes, which have corresponding cyclic peptide products, and the structure of $A m P O P B$, were predicted on Splign website and confirmed by cloning. All five MSDIN genes contain four exons and three introns each, similar to those from other lethal Amanita species. AmPOPB contained 18 exons and 17 introns and encoded 731 amino acids. Nucleotide sequences, amino acid sequences and structures for these genes are displayed in Supplementary file S4 and Figure S1. 
a

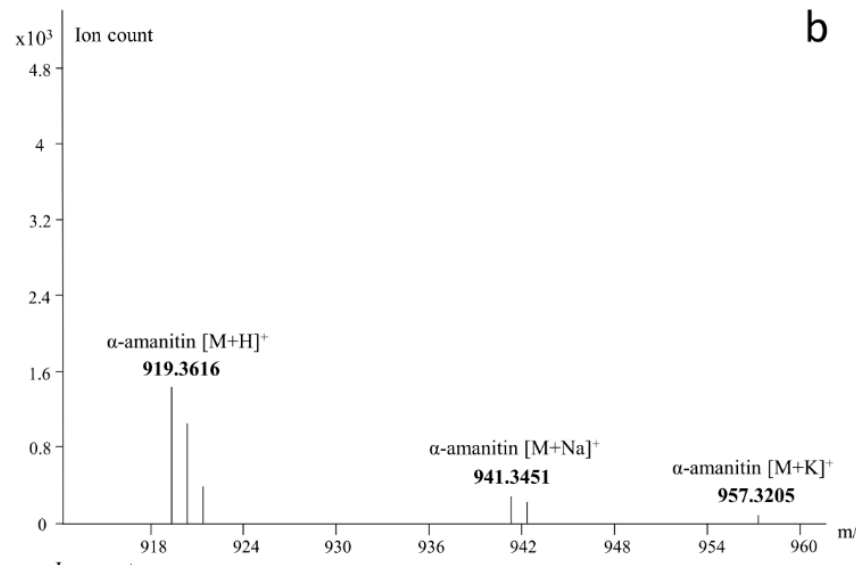

C

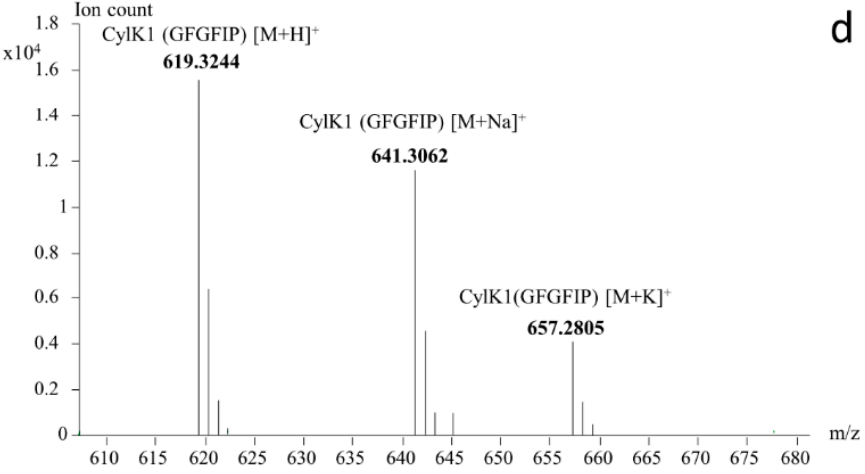

b

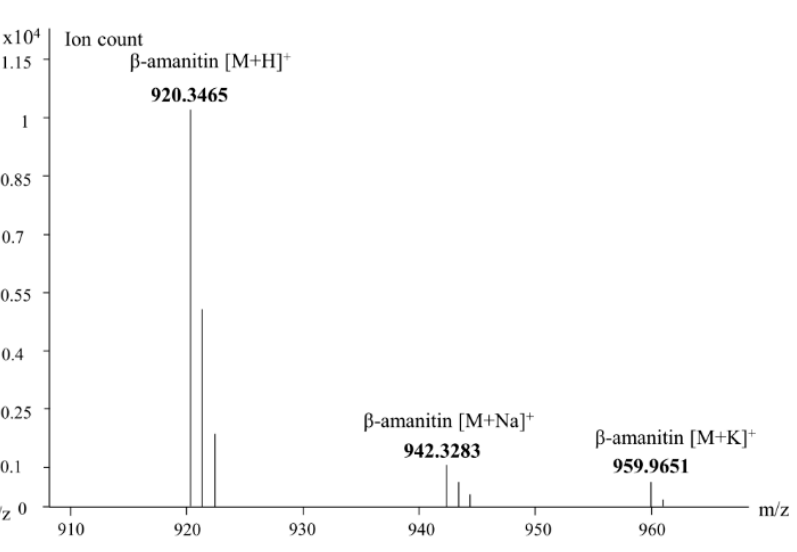

d

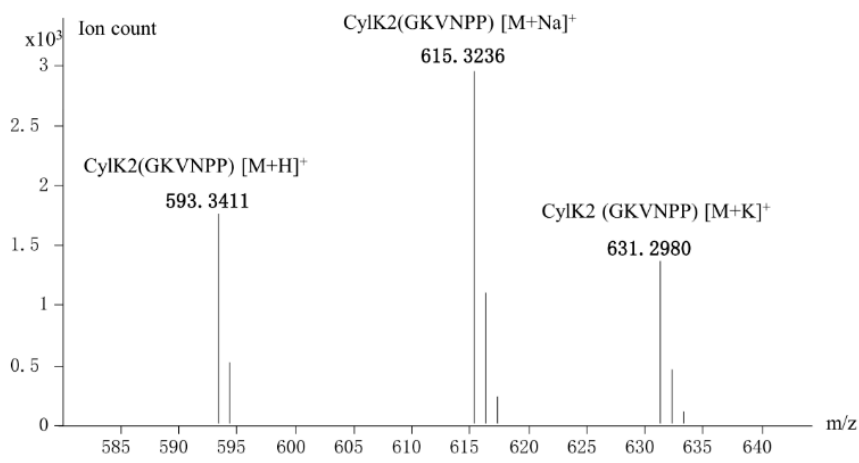

e

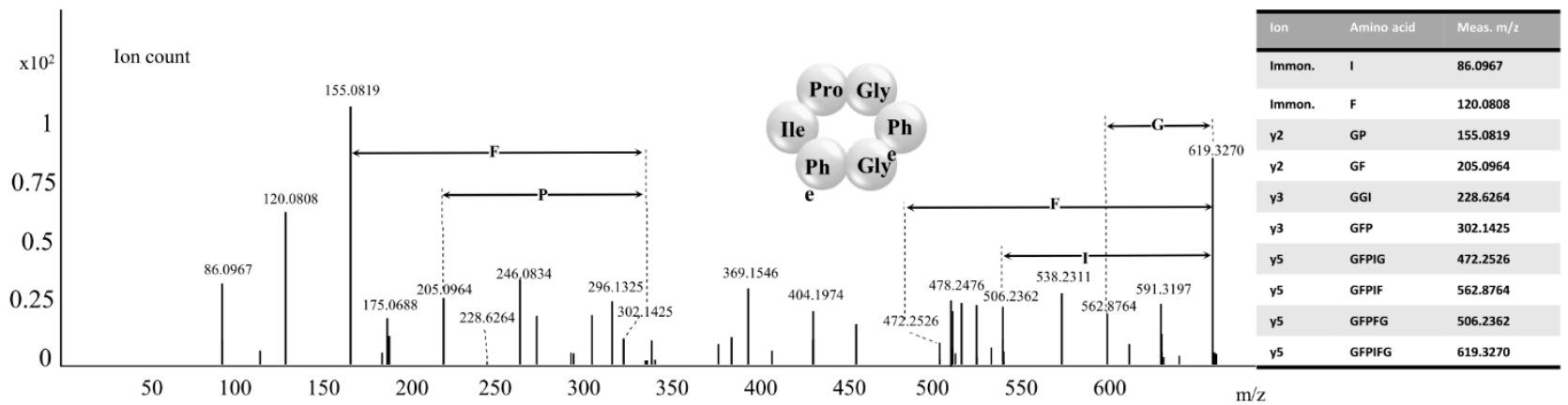

f

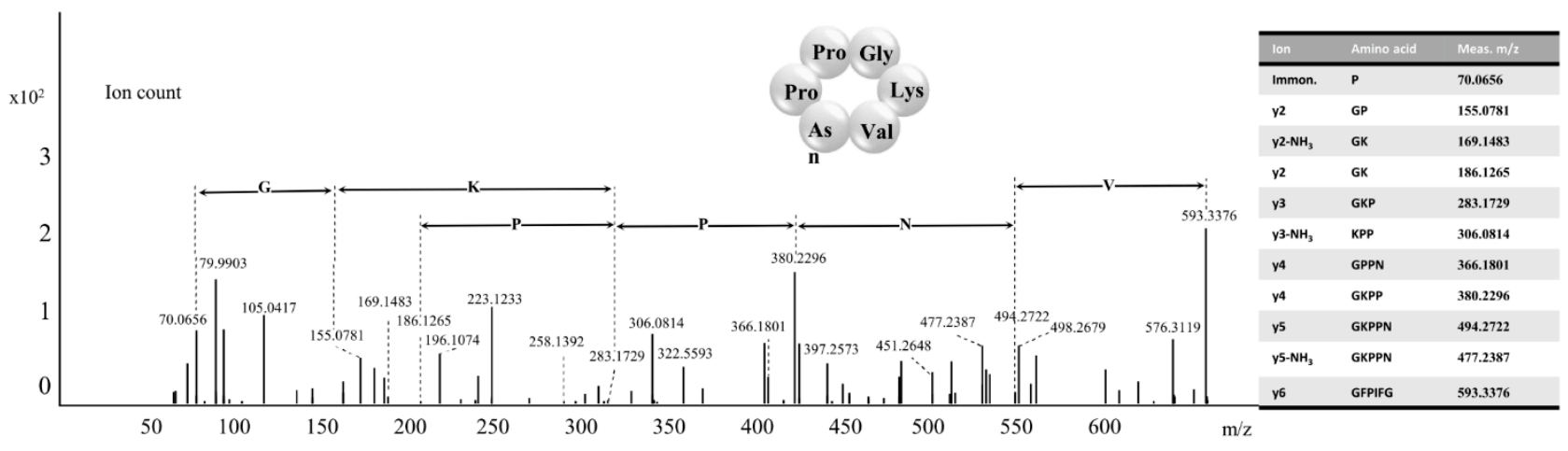

Figure 4. Mass spectrometry spectrograms of known and novel cyclic peptides produced in Amanita molliuscula ((a): $\alpha$ amanitin, (b): $\beta$-amanitin, (c): CylK1 (Cyclo(GFGFIP)), (d): CylK2 (Cyclo (GKVNPP)). Manual analysis of MS/MS fragmentation of the two novel cyclic peptides, CylK1 (e) and CylK2 (f). 


\section{Discussion}

Amanitin-producing Amanita species are restricted in the sect. Phalloideae, and only the basalmost species in the section do not contain the cyclic peptide toxins [16]. Amanita molliuscula is a basal species found in the lethal Amanita clade and no cases of poisoning have been reported with this species. This mushroom could offer insights into the original form of the amanitin biosynthetic pathway in this genus. This study showed that phallotoxins were not present in the species, which sets it apart from all other known lethal Amanita species. In addition, $\alpha$-amanitin was detected only at trace level, indicating this species is less toxic compared with its allies. In total, 21 genes encoding 17 MSDINs were discovered in A. molliuscula, with 14 MSDINs encoding potential novel cyclic peptides. In addition to 3 MSDINs coding for $\alpha$-amanitin and one for $\beta$-amanitin, the core peptide LNILPFHLPP has been reported in A. pallidorosea [13]. Two novel cyclic peptides (CylK1 and CylK2) were discovered, which are the smallest MSDIN-related cyclic peptides and share no similarity to the others in the group.

All previously known lethal Amanita species produce both amatoxins(s) and phallotoxins(s). In previous studies, six genomes of lethal amanita have been published, i.e., A. bisporigera, A. phalloides, A. subjunquillea, A. pallidorosea, A. exitialis and A. rimosa $[12,18,19]$. These species contain at least three major toxins, while $A$. molliuscula possesses only two amatoxins, i.e., $\alpha$-amanitin (trace amount) and $\beta$-amanitin. Given that it is a basal species of lethal Amanita, this may indicate that the origin of amatoxins predates that of phallotoxins. There are only 17 unduplicated MSDIN sequences in A. molliuscula, showing the least expansion of the MSDIN family $(31,33,24,29,23,29)$ within Amanita. Moreover, the last amino acid residue of the leader peptide in AmAMA2 and $A m A M A 3$ is Ala, while all other MSDINs possess a highly conserved Pro. Collectively, we speculate that many of the above unique characteristics are linked to the fact that this particular species is at the basal position of lethal Amanita species.

Similar to our previous study [19], a majority of the MSDIN genes are expressed at the transcription level in A. molliuscula. Some MSDINs and AmPOPB are highly expressed (compared with housekeeping genes), suggesting that the amanitin biosynthetic pathway is highly active at the mature fruiting-body stage. Further, highly differential expression was found in MSDIN genes, indicating that cyclic peptides are not equally expressed. Our preliminary expression data (without technical replicates) on A. subjunquillea and A. exitialis showed very similar patterns (data not shown). Thus, in the mature fruiting body of A. molliuscula, only a fraction of cyclic peptides are actively synthesized, while most, including the major toxins, are suppressed. It is common knowledge that amanitins are present at all stages of fruiting body development [40,41], indicating these toxins are biosynthesized at early stage(s). Consistently, previous studies on the expression of $\alpha$ amanitin and $\beta$-amanitin in A. exitialis showed that the expression of these genes is higher at the immature stage of the fruiting body [17]. The accumulation of these toxins could inhibit their expression at later stages. Regarding $A m P O P B$ expression, the key enzyme of the pathway, the high expression strongly suggests that the metabolic pathway is actively producing cyclic peptides. The production probably includes CylK1 and CylK2 since the highest transcription was associated with the two underlying MSDINs. The shift of the peptide production may be linked to the functions of these peptides, which may be needed at different developmental stages. In conclusion, there is a clear correlation between transcription level and final cyclic peptide products, as highly expressed MSDINs tend to have detectable peptide products. However, low expression of MSDIN genes may not correlate with peptide accumulation, such as the major toxins, which indicates a sequential biosynthesis of the peptides under a sophisticated control mechanism.

The genome size of A. molliuscula is slightly larger than other sequenced Amanita species. One likely reason is that this species contains higher percentage of transposable elements (64.78\%). AmPOPB is not clustered with any of the MSDIN genes, which is consistent with previous findings [14,18]. MSDIN genes scatter across the genome, but the distribution is not entirely random. Some MSDINs tend to group together (linked 
or close to one another), showing some degree of clustering, while others can be totally isolated by themselves (Figure 2). Based on the transcriptome, grouped MSDINs does not share comparable expression levels; instead, they exhibit differential patterns, showing that even MSDINs in close proximity are not coregulated. AmPOPA, although not an amitin biosynthetic gene, was also checked for clustering, and it is not located near any of the biosynthetic genes. Overall, our results confirmed that amanitin biosynthetic pathway does not assume the form of a classic gene cluster, which is consistent with other reports [14,18].

Cyclic peptides produced in Amanita species, such as $\alpha$-amanitin and phalloidin, are valuable natural products [6-9], and only very recently, chemical synthesis of $\alpha$-amanitin is achieved [42-44]. The two novel cyclic peptides (CylK1 and CylK2) discovered in this study have unique structures. Not only are they the first 6-aa cyclic peptides found in amanitinproducing mushrooms, they share no obvious sequence similarity to other cyclic peptides. Before this report, the shortest cyclic peptides comprised 7 amino acids, such as the phallotoxins and virotoxins [1,5]. There are also longer peptides containing up to 10 amino acids, such as antamanide and related peptides $[1,5,19]$. Our recent report showed a cyclic peptide containing 11 amino acids, to date the longest [19]. Both CylK1 (Cyclo(GFGFIP)) and CylK2 (Cyclo(GKVNPP)) have no further posttranslational modifications. They lack Trp and Cys, and therefore no tryptathionine bridge [45] could occur. CylK2 has an alkaline amino acid residue (Lys) with double Pro. In comparison, CylK1 is much more hydrophobic and only has one Pro residue. CylK1 and CylK2 do not share obvious sequence similarities with each other or with any other cyclic peptides, and the novelty of the structure may indicate novel functions. We are synthesizing the peptides for further studies.

\section{Conclusions}

A basal species of amanitin-producing Amanita species, A. molliuscula, was sequenced, yielding 14 novel MSDIN genes. Global expression of amanitin biosynthetic genes was illustrated in the species. At mature fruiting body stage, the pathway is highly active with differential expression of amanitin biosynthetic genes. Led by expression data, two novel cyclic peptides which have novel structure and share no similarity to known cyclic peptides were discovered through a genome-guided approach. The result indicates that MSDIN expression level is associated with final peptide production. Cyclic peptides in A. molliuscula are sequentially expressed; major toxins are not actively expressed at the mature fruiting body stage. This research offers a first in depth look into the expression of amanitin biosynthetic genes.

Supplementary Materials: The following are available online at https: / www.mdpi.com/article / 10.3390/jof7050384/s1, Supplementary file S1: The gene information for phylogenetic reconstruction. Supplementary file S2: The primers for amanitin biosynthetic genes. Supplementary file S3: Comparison of expression of amanitin biosynthetic genes among three technical replicates (Am1, Am2 and Am3). Supplementary file S4: Genomic DNA and amino acid sequences of amanitin biosynthetic genes (introns underlined, start and stop codons in red and core peptides in bold). Figure S1: Structures of amanitin biosynthetic genes in Amanita molliuscula.

Author Contributions: H.L. and Y.L. designed and carried out the genome sequencing. Y.L. analyzed the genome and transcriptomes. S.Z. performed the LC-MS and LC-MS/MS analyses. Y.L. and X.L. performed gene cloning and helped write the manuscript. Z.C. collected the sample. Z.Y. helped improve the final manuscript. H.L. and Y.L. prepared the manuscript. All authors have read and agreed to the published version of the manuscript.

Funding: This research was supported by the Strategic Priority Research Program of the Chinese Academy of Sciences (Grant no. XDB31000000), National Natural Science Foundation of China (Grant no. 31772377 and 31972477$)$.

Institutional Review Board Statement: Not applicable.

Informed Consent Statement: Not applicable. 
Data Availability Statement: The Whole Genome Shotgun assembly was deposited at DDBJ/ENA/ GenBank as part of the accession JAE-BUT000000000.

Acknowledgments: We thank the Yunnan Key Laboratory for Fungal Diversity and Green Development, Kunming, Yunnan, Scientific Research Foundation of the Education Department of Human Resources and Social Security of Yunnan Province, China, and Scientific Research Foundation of Kunming Institute of Botany, Chinese Academy of Sciences. We also thank Ping Zhang for the picture of A. molliuscula.

Conflicts of Interest: The authors declare no conflict of interests.

\section{References}

1. Wieland, T. Peptides of Poisonous Amanita Mushrooms; Springer: Berlin/Heidelberg, Germany, 1986.

2. Li, H.J.; Zhang, H.S.; Zhang, Y.Z.; Zhang, K.P.; Sun, C.Y. Mushroom poisoning outbreaks-China, 2019. China CDC Wkly. 2020, 2, 19-24. [CrossRef]

3. Li, H.J.; Zhang, H.S.; Zhang, Y.Z.; Zhou, J.; Yin, Y.; He, Q.; Jiang, S.F.; Ma, P.B.; Zhang, Y.T.; Wen, K.; et al. Mushroom poisoning outbreaks-China, 2020. China CDC Wkly. 2021, 3, 41-45. [CrossRef]

4. Chen, Z.H.; Yang, Z.L.; Bau, T.; Li, T.H. Poisonous Mushrooms: Recognition and Poisoning Treatment; Science Press: Beijing, China, 2016.

5. Walton, J.D. The Cyclic Peptide Toxins of Amanita and Other Poisonous Mushrooms; Springer International Publishing AG: Cham, Switzerland, 2018.

6. Greenleaf, A.L.B.; Leslie, M.; Jiamachello, P.F.; Coulter, D.E. $\alpha$-Amanitin-resistant D. melanogaster with an altered RNA polymerase II. Cell 1979, 18, 613-622. [CrossRef]

7. Bushnell, D.A.; Patrick, C.; Kornberg, R.D. Structural basis of transcription: $\alpha$-Amanitin-RNA polymerase II cocrystal at $2.8 \AA$ resolution. Proc. Natl. Acad. Sci. USA 2002, 99, 1218-1222. [CrossRef] [PubMed]

8. Kume, K.; Ikeda, M.; Miura, S.; Ito, K.; Sato, K.A.; Ohmori, Y.; Endo, F.; Katagiri, H.; Ishida, K.; Ito, C.; et al. $\alpha$-Amanitin restrains cancer relapse from drug-tolerant cell subpopulations via TAF15. Sci. Rep. 2016, 6, 25895. [CrossRef]

9. Liu, Y.; Zhang, X.; Han, C.; Wan, G.; Huang, X.; Ivan, C.; Jiang, D.; Rodriguez-Aguayo, C.; Lopez-Berestein, G.; Rao, P.H.; et al. TP53 loss creates therapeutic vulnerability in colorectal cancer. Nature 2015, 520, 697-701. [CrossRef]

10. Luo, H.; Hong, S.Y.; Sgambelluri, R.M.; Angelos, E.; Li, X.; Walton, J.D. Peptide macrocyclization catalyzed by a prolyl oligopeptidase involved in $\alpha$-amanitin biosynthesis. Chem. Biol. 2014, 21, 1610-1617. [CrossRef]

11. Sgambelluri, R.M.; Smith, M.O.; Walton, J.D. Versatility of prolyl oligopeptidase B in peptide macrocyclization. ACS. Synth. Biol. 2018, 7, 145-152. [CrossRef] [PubMed]

12. Hallen, H.E.; Luo, H.; Scott-Craig, J.S.; Walton, J.D. Gene family encoding the major toxins of lethal Amanita mushrooms. Proc. Natl. Acad. Sci. USA 2007, 104, 19097-19101. [CrossRef]

13. Luo, H.; Cai, Q.; Lüli, Y.J.; Li, X.; Sinha, R.; Hallen-Adams, H.E.; Yang, Z.L. The MSDIN family in amanitin-producing mushrooms and evolution of the prolyl oligopeptidase genes. IMA Fungus 2018, 9, 225-242. [CrossRef] [PubMed]

14. Lüli, Y.J.; Cai, Q.; Chen, Z.H.; Sun, H.; Zhu, X.T.; Li, X.; Yang, Z.L.; Luo, H. Genome of lethal Lepiota venenata and insights into the evolution of toxin-biosynthetic genes. BMC Genom. 2019, 20, 198. [CrossRef] [PubMed]

15. Luo, H.; Hallen-Adams, H.E.; Scott-Craig, J.S.; Walton, J.D. Ribosomal biosynthesis of $\alpha$-amanitin in Galerina marginata. Fungal Genet. Biol. 2012, 49, 123-129. [CrossRef] [PubMed]

16. Cai, Q.; Tulloss, R.E.; Tang, L.P.; Tolgor, B.; Zhang, P.; Chen, Z.H.; Yang, Z.L. Multi-locus phylogeny of lethal amanitas: Implications for species diversity and historical biogeography. BMC Evol. Biol. 2014, 14, 143. [CrossRef] [PubMed]

17. Li, P.; Deng, W.Q.; Li, T.H.; Song, B.; Shen, Y.H. Illumina-based de novo transcriptome sequencing and analysis of Amanita exitialis basidiocarps. Gene 2013, 532, 63-71. [CrossRef]

18. Pulman, J.A.; Childs, K.L.; Sgambelluri, R.M.; Walton, J.D. Expansion and diversification of the MSDIN family of cyclic peptide genes in the poisonous agarics Amanita phalloides and A. bisporigera. BMC Genom. 2016, 17, 1038. [CrossRef] [PubMed]

19. Zhou, S.W.; Li, X.C.; Lüli, Y.J.; Li, X.; Chen, Z.H.; Yuan, P.C.; Yang, Z.L.; Li, G.H.; Luo, H. Novel cyclic peptides from lethal Amanita mushrooms through a genome-guided approach. J. Fungi 2021, 7, 204. [CrossRef]

20. Cai, Q.; Cui, Y.Y.; Yang, Z.L. Lethal Amanita species in China. Mycologia 2016, 5, 993-1009.

21. Kazutaka, K.; Daron, M.S. A simple method to control over-alignment in the MAFFT multiple sequence alignment program. Bioinformatics 2016, 32, 1933-1942.

22. Hall, T.A. BioEdit: A user-friendly biological sequence alignment editor and analysis program for Windows 95/98/NT. Nucleic Acids Symp. Ser. 1999, 41, 95-98.

23. Stamatakis, A. RAxML-VI-HPC: Maximum likelihood-based phylogenetic analyses with thousands of taxa and mixed models. Bioinformatics 2006, 22, 2688-2690. [CrossRef]

24. Ronquist, F.; Huelsenbeck, J.P. MrBayes 3: Bayesian phylogenetic inference under mixed models. Bioinformatics 2003, 19, 1572-1574. [CrossRef]

25. Nylander, J.A. MrModeltest v2.2; Program distributed by the author; Evolutionary Biology Centre, Uppsala University: Uppsala, Sweden, 2004 
26. Seppey, M.; Manni, M.; Zdobnov, E.M. BUSCO: Assessing genome assembly and annotation completeness. Methods Mol. Biol. 2019, 1962, 227-245. [PubMed]

27. Chen, S.; Zhou, Y.; Chen, Y.; Jia, G. Fastp: An ultra-fast all-in-one fastq preprocessor. Bioinformatics 2018, 34, i884-i890. [CrossRef] [PubMed]

28. Kim, D.; Landmead, B.; Salzberg, S.L. HISAT: A fast spliced aligner with low memory requirements. Nat. Methods 2015, 12, 357-360. [CrossRef]

29. Li, H.; Handsaker, B.; Wysoker, A.; Fennell, T.; Ruan, J.; Homer, N.; Marth, G.; Abecasis, G.; Durbin, R. The Sequence Alignment/Map (SAM) format and SAMtools. Bioinformatics 2009, 25, 2078-2079. [CrossRef]

30. Yang, L.; Smyth, G.K.; Wei, S. The subread aligner: Fast, accurate and scalable read mapping by seed-and-vote. Nucleic Acids Res. 2013, 10, e108.

31. Love, M.I.; Huber, W.; Anders, S. Moderated estimation of fold change and dispersion for RNA-seq data with DESeq2. Genome Biol. 2014, 15, 550. [CrossRef]

32. Pertea, M.; Pertea, G.M.; Antonescu, C.M.; Chang, T.C.; Mendell, J.T.; Salzberg, S.L. StringTie enables improved reconstruction of a transcriptome from RNA-seq reads. Nat. Biotechnol. 2015, 33, 290-295. [CrossRef]

33. Emms, D.; Kelly, S. OrthoFinder: Solving fundamental biases in whole genome comparisons dramatically improves orthogroup inference accuracy. Genome Biol. 2015, 16, 157. [CrossRef]

34. Krzywinski, M.; Schein, J.; Birol, I. Circos: An information aesthetic for comparative genomics. Genome Res. 2009, 19, 1639-1645. [CrossRef]

35. Soderlund, C.; Bomhoff, M.; Nelson, W.M. SyMAP v3.4: A turnkey synteny system with application to plant genomes. Nucleic Acids Res. 2011, 39, e68. [CrossRef] [PubMed]

36. Hallen, H.E.; Watling, R.; Adams, G.C. Taxonomy and toxicity of Conocybe lactea and related species. Mycol. Res. 2003, 107, 969-979. [CrossRef] [PubMed]

37. Enjalbert, F.; Gallion, C.; Jehl, F.; Monteil, H.; Faulstich, H. Simultaneous assay for amatoxins and phallotoxins in Amanita phalloides by high-performance liquid chromatography. J. Chromatogr. 1992, 598, 227-236. [CrossRef]

38. Cui, Y.Y.; Cai, Q.; Tang, L.P.; Liu, J.W.; Yang, Z.L. The family Amanitaceae: Molecular phylogeny, higher-rank taxonomy and the species in China. Fungal Divers. 2018, 91, 5-230. [CrossRef]

39. Yang, Z.L. Atlas of the Chinese Species of Amanitaceae; Science Press: Beijing, China, 2015.

40. Li, P.; Deng, W.Q.; Li, T.H. The molecular diversity of toxin gene families in lethal Amanita mushrooms. Toxicon 2014, 83, 59-68. [CrossRef] [PubMed]

41. Zhang, C.H.; Zou, J.P.; Deng, W.Q.; Li, T.H.; Jiang, Z.D. Molecular cloning and the expression pattern of AePOPB involved in the $\alpha$-amanitin biosynthesis in Amanita exitialis fruiting bodies. Gene 2018, 662, 123-130. [CrossRef] [PubMed]

42. Lutz, C.; Simon, W.; Werner-Simon, S.; Pahl, A.; Muller, C. Total synthesis of $\alpha$-and $\beta$-amanitin. Angew. Chem. Int. Ed. 2020, 59, 11390-11393. [CrossRef] [PubMed]

43. Matinkhoo, K.; Pryyma, A.; Todorovic, M.; Patrick, B.O.; Perrin, D.M. Synthesis of the death-cap mushroom toxin $\alpha$-amanitin. J. Am. Chem. Soc. 2018, 140, 6513-6517. [CrossRef]

44. Siegert, M.J.; Knittel, C.H.; Sussmuth, R.D. A convergent total synthesis of the death cap toxin $\alpha$-amanitin. Angew. Chem. Int. Ed. 2019, 59, 5500-5504. [CrossRef]

45. May, J.P.; Perrin, D.M. Tryptathionine bridges in peptide synthesis. Biopolymers 2010, 88, 714-724. [CrossRef] 